\title{
SYNDROMIC FORM OF OROFACIAL CLEFTING: VAN DER WOUDE SYNDROME
}

\author{
Amanda Affonsêca Pedreira \\ Student of Post-graduation Program of Stomatology. \\ Bahiana School of Medicine and Public Health, Salva- \\ dor, Bahia, Brazil. \\ Andréa do Rego Borges \\ Student of Post-graduation Program of Stomatology. \\ Bahiana School of Medicine and Public Health, Salva- \\ dor, Bahia, Brazil. \\ Elisabeth Martinez Student of Dentistry Course. Bahiana School of Medici- \\ ne and Public Health, Salvador, Bahia, Brazil. \\ Patricia de Castro Veiga MD, Research Group in Oral Pathology. Bahiana School \\ of Medicine and Public Health, Salvador, Bahia, Brazil. \\ Alena Peixoto Medrado \\ MD, PhD, Adjunct Professor, Departament of Basic Scien- \\ ce .Research Group in Oral Pathology. Bahiana School of \\ Medicine and Public Health, Salvador, Bahia, Brazil. \\ Siluia Regina de Almeida Reis \\ PhD, Adjunct Professor, Departament of Basic Science. \\ Research Group in Oral Pathology. Bahiana School of \\ Medicine and Public Health, Salvador, Bahia, Brazil.
}

Corresponding author

Silvia Regina de Almeida Reis

E-mail: srareis@bahiana.edu.br

\begin{abstract}
The Van der Woude Syndrome (VWS) is a rare congenital malformation, clinically characterized by the presence of lower lip pits, cleft lip and/or palate and occasionally, hypodontia. The present report presents a clinical case of VWS, and emphasizes the role of the dentist as the first person to diagnose this syndrome.
\end{abstract}

Keywords: Van der Woude Syndrome; Cleft lip and/ or palate; Lower lip pits.

\section{INTRODUCTION}

The Van der Woude (VWS) Syndrome is a congenital malformation, genetically inherited by a autosomal dominant trait, of incomplete penetrance and clinically characterized by the presence of lower lip pits, cleft lip and/ or palate, and occasionally hypodontia. In spite of van der Woude having described this pathology in 1954, and hav- 
ing studied it intensely, the first reports were made in 1845 by Demarquaz and in 1860 by Murray. ${ }^{(1)}$

As it concerns a rather uncommon anomaly that affects approximately 2 in every 40,000 to 100,000 live births, ${ }^{(2)}$ the aim of this report is to present a clinical case of VWS with emphasis on its main clinical characteristics.

\section{CLINICAL CASE}

The patient, a 7-year-old girl with bilateral bottom lip pits, bilateral cleft lip and palate - operated, and clinical absence of teeth 11 and 21. The panoramic radiograph showed supernumerary teeth in the region of the left and right maxillary lateral incisors, denominated precanines, one of them impacted and agenesis of teeth 12 and 22. (Figure 1) The patient had been submitted to two cheloplasty procedures and surgical closure of the cleft lip and palate. The first surgery was performed ten months after birth and the second at five years of age. The family history showed mother and sister with bilateral cleft lip, with absence of lower lip pits. The presence of other cases of cleft lip and/or palate in the family was related, among them the father and paternal grandfather. The patient affirmed having good performance at school and no otalgia, otorrhea was observed. The patient denied having difficulties with chewing and swallowing. According to the clinical findings associated with the family, the diagnosis of van der Woude Syndrome was established. At present dental and medical follow-up of the patient is being performed.

Figure 1 - Van der Woude syndrome

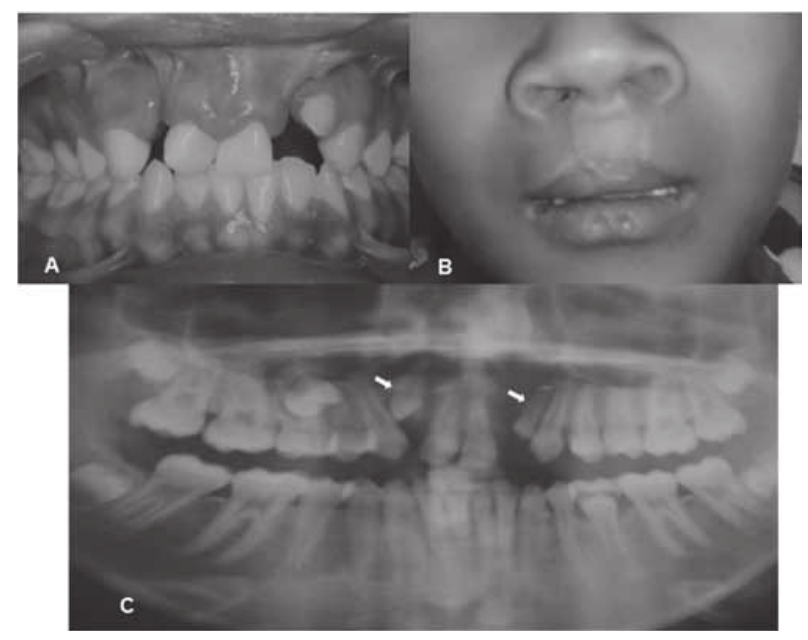

A. Bilateral cleft. B. Symmetric lower lip pits. C. Panoramic radiograph: precanine supernumerary teeth (arrows). 


\section{DISCUSSION}

The van der Woude Syndrome has a highly variable expression, with different phenotypes that show, for example, a hardly evident depression through to congenital pits in the bottom lip. The presence of orofacial clefts vary from bifid uvula to complete clefts. ${ }^{(3)}$

In this disease, other less common anomalies may be observed, such as maxillary and mandibular adherence, absence of the maxillary lateral incisors, ankyloglossia and bifid uvula. ${ }^{(4)}$ The dental anomalies are considered a cardinal sign of VWS. ${ }^{(5)}$

The patient in this study, in addition to the classical clinical presentation of VWS, also has dental anomalies such as giroversion, "precanine" supernumerary teeth and hypodontia of the maxillary lateral incisors. In the literature, these characteristics in the same patient are not common. In the cases described, when there is presence of supernumerary teeth, hypodontias are not shown.

The family occurrence of VWS ranges from $50 \%$ to $60 \%$, and its variability of expression for members of the family that have the same mutation suggests multifactorial influences, similar to those of non-syndromic clefts. The remainder of the cases occur with new forms of mutation. ${ }^{(5,6)}$ According to Burdick et al $(1985),{ }^{(7)} 15 \%$ of those with the syndrome do not present lip pits, and these individual are clinically undistinguishable from those who present isolated non syndromic clefts. In the case under study, various members of the patient's family with VWS have cleft lips, but none of them presented lower lip pits. One understands that these individuals may have the van der Woude Syndrome, in spite of the clinical characteristics not being sufficient to define the diagnosis. It is known that over 300 syndromes exhibit cleft lip and palate as one of the characteristics. ${ }^{(8)}$

In the literature, the van der Woude Syndrome is considered a Mendelian disorder. Its genetic origin is attributed to microdeletions in chromosomal bands 1q32q41, which belong to gene IRF6. Sertié et al. ${ }^{(9)}$ have suggested the association of another gene, 17p11.2-11.1, especially in those patients who have the syndrome with a cleft palate, and have affirmed that the Mendelian concept of monogenic disease for VWS appears to be increasingly unsustainable.

The popliteal pterygium syndrome (PPS) is frequently referred to in the differential diagnosis of VWS. It is characterized by the same clinical signs as those of VWS, in addition to abnormalities of the lower limbs and nails, adhesion of the popliteal membrane, ankyloglossia and genital anomalies, including cryptorchidism, bifid scrotum and uterine hypoplasia. ${ }^{(10)}$ It is associated with mutations in gene IRF6, also attributed to VWS. In the patient under study, who has VWS, the clinical alterations described were not observed. 
The dentist should recognize and diagnose this syndrome, especially at the beginning of life, and establish adequate treatment. The participation of various medical and dental specialties will provide individuals with VWS good esthetic-functional conditions. The patient in this study was submitted to various corrective surgical procedures and is being followed up by a phonoaudiologist. In addition, she is undergoing orthodontic, clinical dental and surgical treatment for the correction of malocclusion, supernumerary teeth, and replacement of absent teeth.

\section{REFERENCES}

1. Van Der Woude A. Fistula labii inferioris congenita and its association with cleft lip and palate. Am J Hum Genet. 1954; 6:244-256.

2. Puvabanditsin S, Garrow E, Sitburana O, Avila FM, Nabong MY, Biswas A. Syngnathia and van der Woude Syndrome: A Case Report and Literature Review. Cleft Palate-Craniofac J. 2003;40(1):104-6.

3. Arangannal P, Muthu MS, Nirmal L. Van der Woude syndrome: a case report. J Indian Soc Pedod Prev Dent. 2002; 20(3):102-103.

4. Reddy RS, Ramesh T, VijaYalaxmi N, Reddy RL, Swapna LA, Singh, T. van der Woude syndrome a syndromic form of orofacial clefting. J Clin Exp Dent. 2012; 4(2):125-8.

5. Rizos M, Spyropoulos MN. van der Woude syndrome: a review. Cardinal signs, epidemiology, associated features, differential diagnosis, expressivity, genetic counselling and treatment. Eur J Orthod. 2004; 26:17-24.

6. Huang JJ, Hou JW, Tan YC, Chen KT, Lo LJ, Chen YR. Van der Woude syndrome: clinical presentation in 64 patients. Cleft Palate Craniofac J. 2007;44(6):649-52.

7. Little HJ, Rorick NK, Su LI, Baldock C, Malhotra S, Jowitt T et al. Missense mutations that cause van der Woude syndrome and popliteal pterygium syndrome affect the DNA-binding and transcriptional activation functions of IRF6. Hum Mol Genet. 2009;18(3):535-45.

8. Burdick AB, Bixler D, Puckett CL: Genetic analysis in families with van der Woude syndrome. J Craniofac Genet Dev Biol. 1985;5:181-208.

9. Murray JC: Gene/environment causes of cleft lip and/or palate. Clin Genet. 2002;61:248-256.

10. Sertié AL, Souza AV, Steman S, Pavanello RC, Passos-Bueno MR. Linkage analysis in large Brazilian Family with van der Woude syndrome suggests the existence of a susceptibility locus for cleft palate at 17p11.2-11.1. Am J Hum Genet. 1999;65(2):433-40

11. Kondo S, Schutte BC, Richardson RJ et al. Mutations in IRF6 cause van der Woude and popliteal pterygium syndromes. Nat Genet. 2002;32(2):285-9.

188 / Brazilian Journal of Medicine Health. 2013 Ago; 2(1):185-188 